\title{
Fundamental Research on Radiochemistry of Geological Nuclear Waste Disposal
}

\author{
Sergey V. Churakov ${ }^{\text {ab*}}$, Wolfgang Hummela, and Maria Marques Fernandes ${ }^{a}$
}

\begin{abstract}
Currently, $5 \cdot 10^{19} \mathrm{~Bq}$ of radioactive waste originating from the use of nuclear power for energy production, and medicine, industry and research, is maintained in Switzerland at intermediate storage facilities. ${ }^{[1]}$ Deep geological disposal of nuclear waste is considered as the most reliable and sustainable long-term solution worldwide. Alike the other European countries, the Swiss waste disposal concept embarks on the combination of engineered and geological barriers. The disposal cell is a complex geochemical system. The radionuclide mobility and consequently radiological impact depend not only on their chemical speciation but also on the background concentration of other stable nuclides and their behaviour in the natural environment. The safety assessment of the repository is thus a complex multidisciplinary problem requiring knowledge in chemical thermodynamics, structural chemistry, fluid dynamics, geo- and radiochemistry. Broad aspects of radionuclide thermodynamics and geochemistry are investigated in state-of-the-art radiochemical laboratories at the Paul Scherrer Institute. The research conducted over the last 30 years has resulted in a fundamental understanding of the radionuclides release, retention and transport mechanism in the repository system.
\end{abstract}

Keywords: Nuclear waste disposal $\cdot$ Radionuclide geochemistry $\cdot$ Radionuclide retention and transport

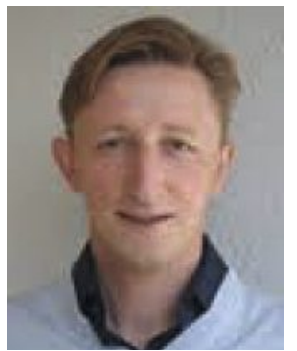

Sergey V. Churakov is Head of Laboratory of Waste Management in the Department of Nuclear Energy and Safety at the Paul Scherrer Institute (PSI) and Full Professor in the Institute of Geological Sciences at the University of Bern (UniBe). He studied Geochemistry and Applied Mathematics at Moscow State University in Russia. He started his research carrier at the GeoForschungsZentrum Potsdam and obtained his PhD in Natural Sciences at the Technical University of Berlin in Germany. Before joining PSI and UniBe, he completed postdoctoral projects at the Swiss Center of Scientific Computing and at the Department of Physical Chemistry and Computational Bio-Sciences at ETH Zurich. His research covers multidisciplinary topics of environmental geochemistry and mineralogy with specific focus on mechanistic understanding of transport and retention of hazardous contaminants and radionuclides in natural environment and geotechnical systems.

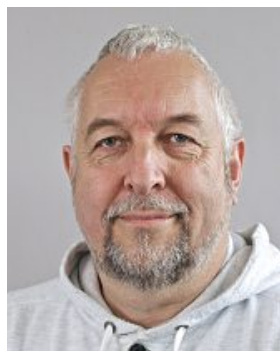

Wolfgang Hummel is Senior Scientist in the Laboratory for Waste Management in the Department of Nuclear Energy and Safety at the Paul Scherrer Institute (PSI) and Lecturer at the ETH Zurich. He studied Mineralogy and Crystallography at the University of Tübingen (Germany) and obtained a $\mathrm{PhD}$ in Natural Sciences at University of Bern. His research covers geochemical modelling of natural organic substances, chemotoxic and radiotoxic contaminants in natural environments and geotechnical systems, and a long-term commitment to the review and evaluation of chemical thermodynamic data and the development of the PSI Chemical Thermodynamic Database.

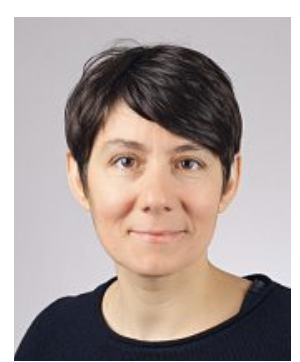

Maria Marques Fernandes is head of the Clay Sorption group in the Laboratory for Waste Management in the Department of Nuclear Energy and Safety at the Paul Scherrer Institute (PSI). She studied Applied Physics and Geophysics at the University Joseph Fourier, Grenoble (France) and obtained a PhD in Natural Sciences at the University of Heidelberg (Germany). She joined the Laboratory for Waste Management in 2006 in the framework of a Marie-Curie Intra-European fellowship. Her research focuses on the mechanistic understanding of the retention of hazardous contaminants and radionuclides in clay-rich environments.

\section{Introduction}

Radioactive waste in Switzerland arises from the use of nuclear power for electricity production, operation of large-scale research facilities, dedicated industrial applications, medical diagnostics and radiopharmacy. Due to the potentially high environmental impact associated with the waste treatment and its disposal, the development and application of adequate technologies have wide societal dimension and resonance. Independent of the further technological developments, a safe and socially acceptable solution for the radioactive waste already existing in Switzerland has to be implemented. Currently, the geological disposal of radioactive waste is recognized internationally and accordingly pursued in Switzerland, as the most sustainable solution ensuring the longterm protection of the environment from potential detrimental radiological impact. Even though the radiotoxicity decreases with time, the unconceivably long period of time required for the waste isolation in comparison to existence of mankind, understandably creates a perception of risk and uncertainty. In this context, 
scientific basis for the comprehension of the long-term radionuclide geochemistry is one of the key ingredients for implementing a technically safe solution for the disposal of radioactive waste in Europe and in Switzerland in particular. Another dimension is related to the dissemination of the relevant scientific knowledge to the general public, building up the chain of argument and gaining the trust of the society for the proposed engineered solution. Finally, education in the field of radiochemistry and geochemistry is essential for raising the next generation of young scientists who will be the main carrier and safeguard of scientific knowledge in the future.

Currently about 6'000 $\mathrm{m}^{3}$ of radioactive waste from the Swiss nuclear power plants are stored in the intermediate storage facility ZWILAG and in on-site facilities at nuclear power plants (Fig. 1). An additional 1'600 $\mathrm{m}^{3}$ of radioactive waste from medicine, industry and research (MIF waste) are stored in the Federal interim storage facility, BZL, at the premises of Paul Scherrer Institute. The Swiss Nationale Genossenschaft für die Lagerung radioaktiver Abfälle (Nagra) anticipates about 44'300 $\mathrm{m}^{3}$ of radioactive waste in total to be accumulated by the mid- $21^{\text {st }}$ century. These quantities will be composed of about $1^{\prime} 500 \mathrm{~m}^{3}$ of high level waste and about $28^{\prime} 400 \mathrm{~m}^{3}$ of low and intermediate level waste (L/ILW) from the Swiss nuclear power plants as well as about $14^{\prime} 400 \mathrm{~m}^{3}$ of MIF waste. All these volumes refer to conditioned waste only, without the final disposal containers. The total volume of the final disposal containers will be about the same as the total volume of the conditioned waste (https://www.nagra.ch/en/volumesen.htm).

The geological options for the disposal of radioactive waste are based on protection through in-depth concepts involving a technical and geological system of barriers. ${ }^{[2]}$ Each element of the barrier system performs or contributes to one or multiple postclosure safety functions (Fig. 1):

- isolation from the surface environment of the waste and of those elements of the barrier system, the integrity of which contributes to post-closure safety;

- complete containment of the waste for a certain time;

- immobilization, retention and slow release of radionuclides;

- compatibility of the barrier system with regard to internal processes involving the barrier elements with each other and other materials, and

- long-term stability of the elements that contribute to postclosure safety, considering the relevant external long-term evolution processes.
Depending on the inventory, it takes $10^{5}-10^{6}$ years for the radioactive waste to decay to the radiotoxicity of natural uranium ore used for production of fuel elements. The employed geochemical barriers have to provide sufficient protection to humans and the environment at all times. One of the fundamental criteria for the assessment of the waste disposal safety is the estimation of the radiological impact of the repository on the biosphere. According to the regulatory requirements for the expected evolution of the repository system or alternative evolutions of non-negligible probability, at no time should the dose exceed the $0.1 \mathrm{mSv} / \mathrm{y}$ limit for a person permanently living there, in a self-sustaining agricultural community. ${ }^{[3]}$ The radiotoxicity of the waste decreases with time according to the known radioactive decay chains. The regulatory limits thus can be met by ensuring the containment of the waste over a long enough period of time in the disposal casks and/or ensuring sufficiently long migration times of the radionuclide in host rocks and finally their dilution.

The source term depends on the given radionuclide inventory and the properties of the waste matrix, e.g. chemical stability, dissolution rates and radionuclide solution/waste matrix partitioning coefficients. The decay rates are specific properties of the radioisotopes. After an initial period of full containment, a complex cocktail of radionuclides and stable isotopes will come into contact with natural pore water, which has been affected by interaction with the technical barriers such as iron corrosion products or cementitious liner. Once the radionuclides are released into the natural aqueous environment, their transport is affected by the properties of host rocks (i.e. diffusivity, connected porosity, hydraulic conductivity) and the interaction with the minerals along the transport path (i.e. reversible or irreversible sorption). The mobility and reactivity of the radionuclides depends on their speciation, which in turn is controlled by the in situ geochemical conditions such as $\mathrm{pH}$-Eh and, more generally, the composition of pore water. A further important parameter relevant for the release and migration of radionuclides is the solubility of radionuclidecontaining phases.

Since the transport and sorption properties of rocks and buffer materials depend on the temperature, pore water chemistry and the degree of mechanical compaction, accurate deterministic description of the transport phenomena requires coupled description of chemical transport, sorption phenomena and thermal conditions. Whenever constant (i.e. time invariant) properties of materials are postulated, it has to be ensured that these properties
Fig. 1. Schematic view of the waste streams in the Swiss waste disposal program and the relevant processes in the repository near field. Original figure (https://www. ensi.ch/en/topic/waste-management/) is reproduced with modifications. Stratigraphic column on the left border of figure indicate lithological location of Opalinus clay formations in the Northern part of Switzerland.
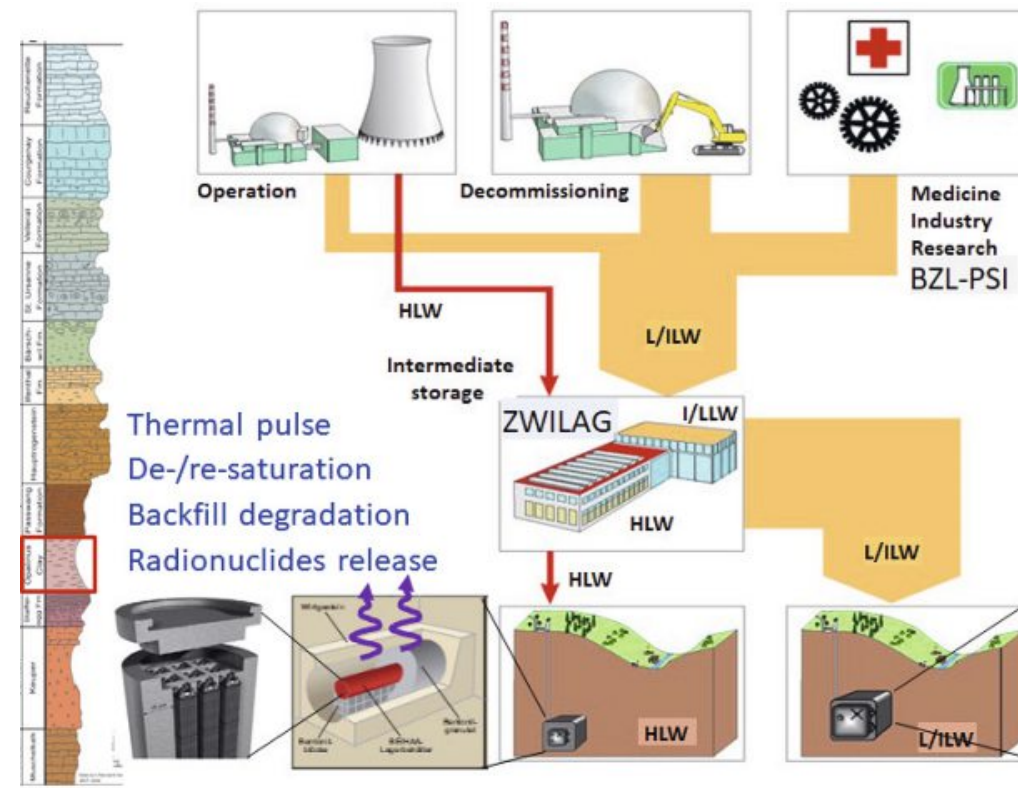
Operation
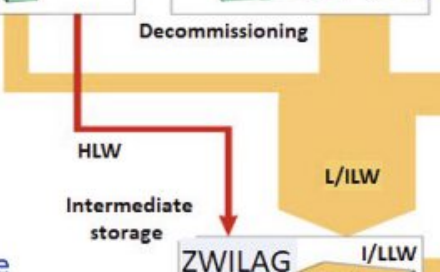

Thermal pulse

De-/re-saturation

Backfill degradation

Radionuclides release
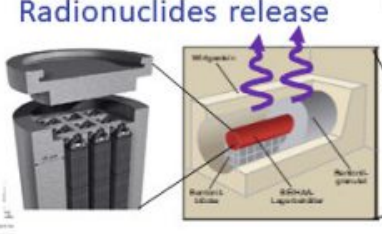

$10^{6} y+2075<-2060<-2050$

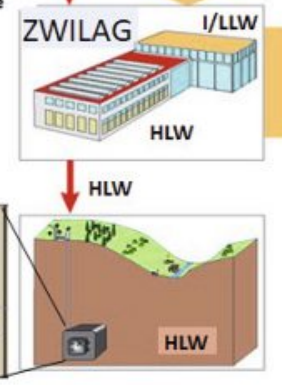

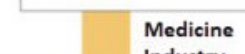

Medicine Research BZL-PSI

$2045->2050->2065+10^{5} y$

http://www.ensi.ch Heterogeneities In situ conditions Waste degradation Release of Gas and radionuclides

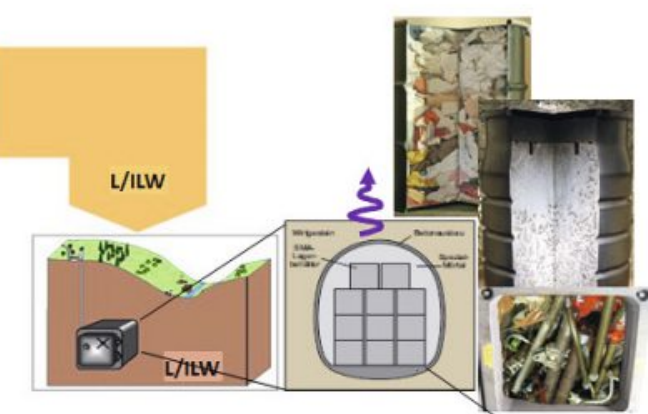


indeed are not affected by thermal or chemical interactions. It is essential to realize that although the radiological impact is determined by the unstable elements, which are in minority by mass, their chemical behaviour is affected by the presence of other, socalled competing stable isotopes with similar chemical behaviour. Thus the consideration of the radionuclides retention and transport in geological systems should not be considered in isolation but coupled to the entire geochemical evolution of the repository.

Assessments of the repository radiological impact cover a time period of more than several hundred thousand years. Such geological timescales are not readily accessible in direct experimental studies. Therefore, long-term assessments of the repository evolution are accomplished on the basis of simplified but conservative model chains. It is essential that such simplified descriptions are supported by more sophisticated mechanistic geochemical models taking full account of structural information about mineral phases and coupling it to the equilibrium thermodynamic and kinetics approach to account for the changing in situ conditions.

The Laboratory for Waste Management (LES, www.psi.ch/les) is the Swiss competence centre for geochemistry and multiscale contaminant transport in deep geological disposal systems. LES is conducting comprehensive research and development (R\&D) studies in support of the Swiss radioactive waste disposal options. The laboratory performs multidisciplinary research on various aspects of radionuclide geochemistry and transport in temporally evolving disposal systems based on experimental studies, development of theoretical models and numerical simulations. The research projects strategically benefit from the physical proximity to unique experimental infrastructure available at PSI such as HOT-laboratories, synchrotron facilities and spallation neutron source for material characterization and imaging. The knowledge obtained in the laboratories is tested in the field at the Grimsel and Mont Terri underground research laboratories. The research activities are well connected with other research groups within the ETH domain, cantonal universities in Switzerland and leading European research units. Particularly, tight links are established with the Institute of Geological Sciences at the University of Bern providing the educational platform in the geochemistry of waste disposal at MSc and $\mathrm{PhD}$ level. Radiochemistry of nuclear waste disposal and fuel cycle is covered in the joint EPFL-ETH nuclear engineering master program.

This article provides an overview of radiochemical knowledge available in Switzerland and the state-of-the-art scientific basis for the evaluation of the long-term geochemical evolution of deep geological repositories. It could also be interesting to see this review in prospective of the scientific progress since an overview paper on waste disposal concepts published in CHIMIA in 2005.[4]

\section{Geochemistry of Multi-barrier System and Waste Inventories}

According to the current Swiss reference disposal concept, ${ }^{[2]}$ Spent Fuel (SF) elements and vitrified waste from reprocessing (HLW) will be disposed off in carbon steel casks, which are designed to sustain anaerobic corrosion for at least 10'000 years after the disposal closure. The casks will be surrounded by highly compacted bentonite buffer, which is expected to saturate and swell so as to protect the disposal cask and contribute to the sealing of the disposal drifts. Upon the breaching of the casks after the initial containment period, the waste matrix inside the casks may come in contact with pore water and a first fraction of nuclides inside the casks will be released instantaneously. Following the initial water ingress, the slow dissolution of the waste forms (e.g. borosilicate glass and spent fuel pellets) controlled by kinetics and/or solubility will lead to a steady release of the radionuclides and their diffusive transport into the surrounding barriers.

The L/ILW waste forms are encapsulated in a cement matrix. Contrary to SF/HLW, the cementitious repository concept in Switzerland does not foresee dedicated containment and bentonite buffer material. The cement and concrete will be in direct contact with the surrounding host rocks. The initial release of radionuclides is expected to start roughly after 100 years after repository closure. The release of the radionuclides from waste matrix to the host rocks will be controlled by the radionuclides interaction with the main cement mineral phases. The release rates of radionuclides depend on the $\mathrm{pH}-\mathrm{Eh}$ in situ conditions, which evolves in the course of cement degradation. Due to the high heterogeneity of the waste materials, the local chemical conditions can vary significantly within the disposal cells, resulting in an increase or decrease of the radionuclide release.

\subsection{Waste Forms SF/HLW}

\subsubsection{Spent Nuclear Fuel}

Spent fuel assemblies, e.g. zirconium alloy rods containing the spent $\mathrm{UO}_{2}$ pellets will be disposed of in massive carbon steel containers. The spent fuel pellets contain, besides 95 wt.\% uranium, about $4 \%$ fission products and about $1 \%$ transuranium elements (mainly plutonium). The spent fuel pellets are full of cracks which are formed during reactor operation and there are also gaps between the fuel pellets and the cladding. During reactor operation, dry storage and initial containment in the repository, the cracks and gaps accumulate the fractions of the more volatile fission products. In a deep geological repository the steel containers will slowly corrode; first using up available oxygen and will then react with water in anaerobic condition, producing hydrogen. Finally, the containers (and the cladding) will breach, triggering fast release of the volatile fission products from the voids into the backfill, followed by a very slow corrosion of the $\mathrm{UO}_{2}$ fuel pellets. Due to the large amounts of corroding $\mathrm{Fe}(0)$ of the steel containers and the slow corrosion of the $\mathrm{UO}_{2}$ fuel pellets, reducing conditions are expected to prevail inside and in the vicinity of the breached containers for geological time scales. Near neutral to slightly alkaline $\mathrm{pH}$ conditions are imposed by the pore water of the bentonite backfill. In the reference case used in the current performance assessment models, it is assumed that all canisters breach after 10'000 years and the first release will take place instantaneously; thus it is called the Instant Release Fraction (IRF). The IRF of easily soluble/volatile nuclides like Cl-36 (5-26 wt.\% of the total inventory of a fuel assembly), I-129 (3-18 wt.\%) and Cs-135 (2-18 wt.\%) have been estimated from leaching data, while the IRF of a less soluble/volatile nuclide like Se-79 (1-11 wt.\%) has been estimated from 'less than' data, (i.e. detection limits, when measurements did not yield detectable concentrations in solution). ${ }^{[5]}$ Recently, it has been shown experimentally that the IRF of Se-79 is negligible to almost non-existent. ${ }^{[6]}$

\subsubsection{Vitrified HLW from Reprocessing}

Vitrified waste from reprocessing consists of cylindrical blocks of borosilicate glass containing roughly $10 \mathrm{wt} . \%$ radionuclides. The leftovers from reprocessing, mainly fission products and the minor actinides $\mathrm{Np}, \mathrm{Am}$ and $\mathrm{Cm}$, are melted together with additives and quenched in steel barrels. The vitrified waste contains neither cracks nor gaps between the glass and the barrel. Hence, there is no IRF associated with this waste form. The vitrified waste blocks will be disposed of in steel containers similar to the ones used for spent nuclear fuel. Accordingly, the redox and $\mathrm{pH}$ conditions are expected to be similar to the ones expected for the spent nuclear fuel. However, the glass corrosion is an order of magnitude faster than the corrosion of the $\mathrm{UO}_{2}$ fuel pellets. In addition, small differences in the glass 'recipes' cause significant differences in the respective glass corrosion rates by about one order of magnitude. ${ }^{[7]}$ The glass corrosion rates used in performance assessment calculations are based on long-term glass corrosion experiments with non-radioactive glass samples where the radio- 
nuclides have been replaced by heavy metals. The by far longestrunning experiments (more than 30 years) have been carried out at LES. Initially measured corrosion rates were found to be very low indicating the formation of slowly reacting passivation surface layers. Over approximately six years, the dissolution rates have been increasing and reached a steady state in the following years, showing that glass corrodes faster than spent fuel. Only $0.1 \%$ of the original I-129 inventory and no Cl-36 (and C-14) is left in vitrified waste from reprocessing. These volatile nuclides had been discharged to the atmosphere and to the ocean by the nuclear reprocessing plants. ${ }^{[8]}$ By contrast, all Se-79 from spent nuclear fuel remains in vitrified waste. It has recently been shown by XANES spectroscopy that selenium in vitrified waste occurs in its anionic tetravalent form $\mathrm{SeO}_{3}{ }^{2-}$.[6a]

\subsection{Waste Forms L/ILW}

Low- and intermediate-level waste originates from the operation and the decommissioning of nuclear power plants, from medicine, industry and research, or structural components from reprocessing. In Switzerland, most of these wastes are conditioned with cement. Additionally, a unique conditioning process is implemented in Switzerland, in which a plasma furnace is used to melt various types of low-level waste and bring it into solidified slag-type massive blocks stored in thin wall steel drums. ${ }^{[9]}$ Besides significant volume reduction, this process eliminates organic matter and thus reduces the potential for gas generation in the repository. The largest volume fraction of L/ILW waste will be the activated reactor steel, delivered from the decommissioning of the Swiss nuclear power plants, and activated structural parts from decommissioned research facilities at PSI and CERN. Cementitious wastes containing large quantities of steel are expected to have a locally reducing environment, while cementitious wastes not containing metallic iron are locally oxidizing. These and other heterogeneities in L/ILW wastes are expected to influence the solubility and sorption behaviour of the radionuclides. For example, 97 mole-\% of Se-79 in L/ILW waste is found in activated reactor steel and, due to the local reducing conditions Se-79 is expected to form aqueous $\mathrm{Se}(\mathrm{aq})$ species in the redox state zero, and its solubility is expected to be very low due to the formation of $\mathrm{FeSe}_{2}(\mathrm{cr})$ and/or $\mathrm{Se}(\mathrm{cr}){ }^{\left[{ }^{[8]}\right.}$ Note that the actual molecular form of $\mathrm{Se}(\mathrm{aq})$ is unknown and it remains to be determined whether $\mathrm{Se}(\mathrm{aq})$ is in 'true solution', e.g. as an $\mathrm{Se}_{8}(\mathrm{aq})$ ring, similar to $S_{8}(\mathrm{aq})$ in the sulphur system, or in the form of Se colloids. ${ }^{[9]}$ In addition to the radionuclides originating from nuclear power plants, the inventory MIRAM14[1] includes several 'exotic' radionuclides coming from the spallation facilities SINQ at PSI (https://www.psi.ch/en/sinq) and ISOLDE (and others) at CERN (https://isolde.web.cern.ch/isolde). Dose-relevant nuclides from these special waste sorts are: Si-32, Al-26, Ti-44, $\mathrm{Fe}-60, \mathrm{Hg}-194, \mathrm{~Pb}-202$ and Po-209. These 'exotic' radionuclides are not yet considered by any other waste management organization, however, the French waste disposal implementer Andra (www.andra.fr) will have to deal with these radioisotopes in the future at least, as they also have to take some of CERN's radioactive waste.

\section{PSI/Nagra Thermodynamic Database and Geochemical Modelling}

The retardation of radionuclides in the near- and far-field of radioactive waste repositories is largely dominated by three processes: solubility limitation by precipitation of radionuclide-bearing minerals, sorption of radionuclides on minerals and slow diffusion controlled mobility in porous media. All these phenomena highly depend on the radionuclide's speciation. The speciation and solubility data should be obtained for well-defined aqueous environments, with the knowledge of the nature of the species involved in the equilibrium reactions under consideration (oxida- tion state, ligands environment), and of the solid phases limiting the solubility. The development of sound thermodynamic databases (TDB) for radionuclide solution speciation and solid formation is therefore a prerequisite for geochemical calculations and thermodynamic model developments in support of safety analyses. It is essential that the database is comprehensive (include necessary elements), internally consistent (with respect to the chemical reactions and the activity models), quality-assured, traceable reported data and internationally recognized. Recent review of the progress in the international databases, traceability, availability, and selfconsistency of available data is summarized in ref. [10].

The PSI/Nagra database ${ }^{[10]}$ is driven by the need for a tailormade thermodynamic database used in safety assessments for planned Swiss geological repositories for radioactive waste. The release of the database contained 'core data' - mainly CODATA key values and other very well established data[11] - and 'supplemental data', basically taken 'in groups' from other databases. [12] The first major update ${ }^{[13]}$ included the NEA TDB reviews on U, $\mathrm{Np}, \mathrm{Pu}, \mathrm{Am}$ and $\mathrm{Tc}$ and own reviews of $\mathrm{Al}, \mathrm{Eu}, \mathrm{Ni}, \mathrm{Pd}, \mathrm{Sn}, \mathrm{Th}$ and $\mathrm{Zr}$. The second update ${ }^{[14]}$ included the NEA TDB reviews on $\mathrm{Ni}, \mathrm{Se}, \mathrm{Zr}$ and $\mathrm{Th}$, the first update for $\mathrm{U}, \mathrm{Np}, \mathrm{Pu}, \mathrm{Am}$ and Tc, and own reviews concerning silicate compounds and complexes. The third major update took place in the period from 2017 to 2020, which included the NEA TDB reviews on Sn, Fe (part 1 and 2), organic ligands and the second update of $\mathrm{U}, \mathrm{Np}, \mathrm{Pu}, \mathrm{Am}$ and Tc. Furthermore, the environmentally important elements $\mathrm{Hg}, \mathrm{Cu}$, $\mathrm{Pb}, \mathrm{Cd}$ and $\mathrm{Zn}$ were added, based on IUPAC reviews and own reviews of sulfide data for these elements. Literature reviews were done for the new elements Ti, Ag, Sm, Ho, Po, Ac and Pa, as well as for the update of $\mathrm{Eu}$ and the major ground and pore water elements $\mathrm{Li}, \mathrm{Na}, \mathrm{K}, \mathrm{Mg}, \mathrm{Ca}, \mathrm{Sr}, \mathrm{Ba}, \mathrm{Mn}$ and $\mathrm{Al}$. A graphical representation of data currently available in the database is shown in Fig. 2. All data are made available in a ready-to-use electronic database of the geochemical speciation code GEMS (http://gems.web.psi.ch/), along with detailed documentation of the data sources.

\section{Sorption Phenomena in Clay Systems}

Illite/smectite phyllosilicate minerals are amongst the most important mineral phases responsible for retention and retardation of radionuclides in engineered technical barriers in a geological waste repository hosted by argillaceous rocks. These phyllosilicate minerals have a layered (TOT) structure, in which two tetrahedral sheets $(\mathrm{T})$ (silica) sandwich an octahedral sheet $(\mathrm{O})$ (dioctahedral aluminum hydroxide or trioctahedral magnesium hydroxide). The TOT layer carries a negative charge originating from the isomorphous substitution of lattice cations by cations of lower valence. This permanent structural charge is counterbalanced by hydrated exchangeable cations. These electrostatic cation exchange reactions are strongly influenced by ionic strength. The most important reactive sites for the retention of radionuclides under relevant geochemical conditions are the surface hydroxyl groups $(\equiv \mathrm{SOH})$ situated at the edges of the clay platelets (Fig. 3). These edge sites protonate and deprotonate as a function of $\mathrm{pH}$ and thus the surface complexation of aqueous radionuclides on the amphoteric edge sites is strongly $\mathrm{pH}$ dependent. Spectroscopic studies and theoretical atomistic modelling suggest that radionuclides form different surface complexes at specific crystallographic positions depending on the nature of the radionuclide, its concentration and prevailing $\mathrm{pH}$ conditions. Such molecular scale information support the development of mechanistic sorption models (e.g. ref. [15]).

The safety assessment of radioactive waste repositories requires a solid understanding of radionuclide migration behaviour in heterogeneous rocks with varying pore water chemistry. The radionuclide's aqueous speciation is controlled by the prevailing in situ geochemical conditions (i.e. $\mathrm{pH}$, Eh, ionic strength, ele- 


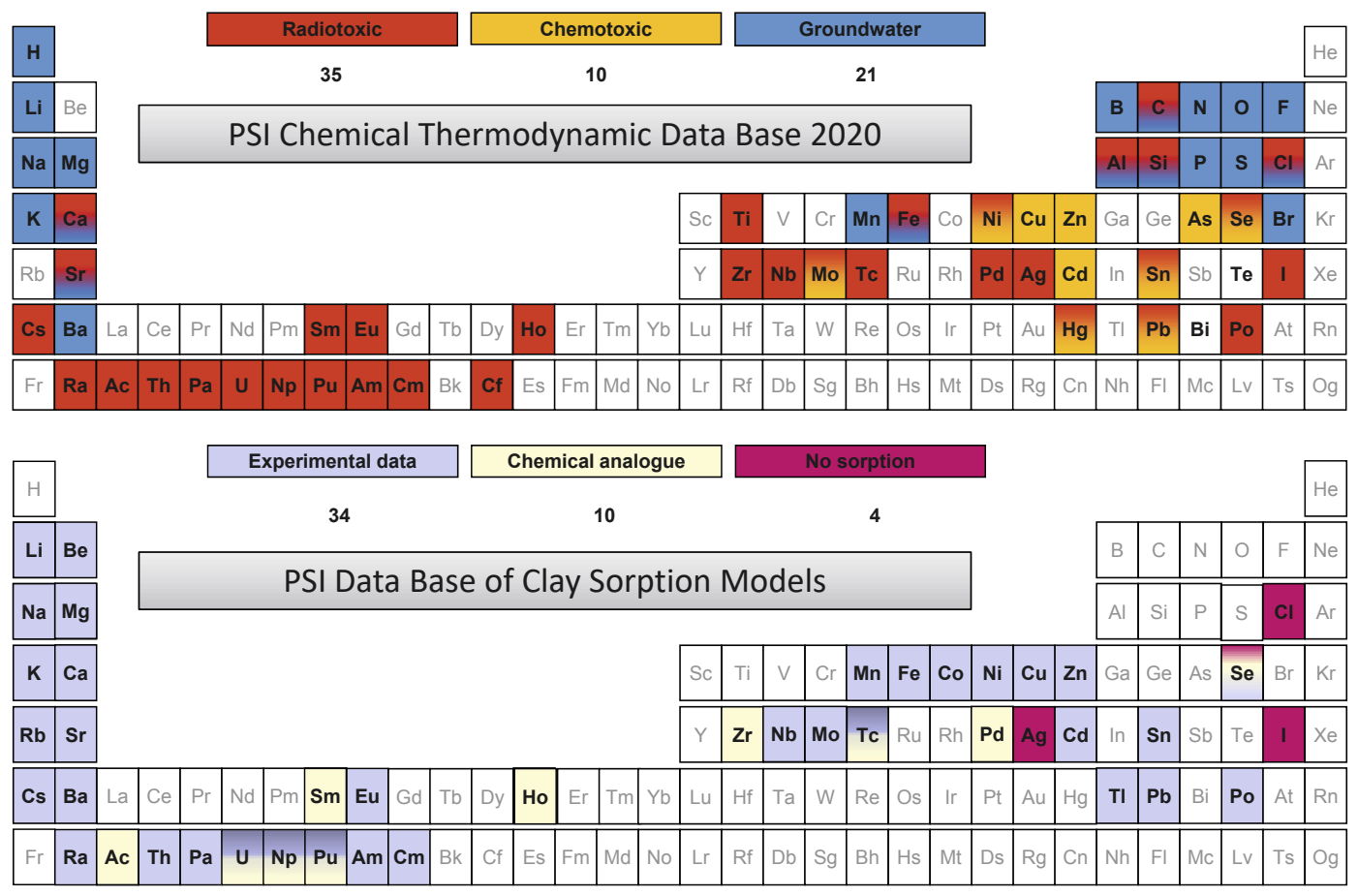

Fig. 2. Chemical elements considered in the PSI chemical thermodynamic database and the ones included into the PSI thermodynamic sorption database.

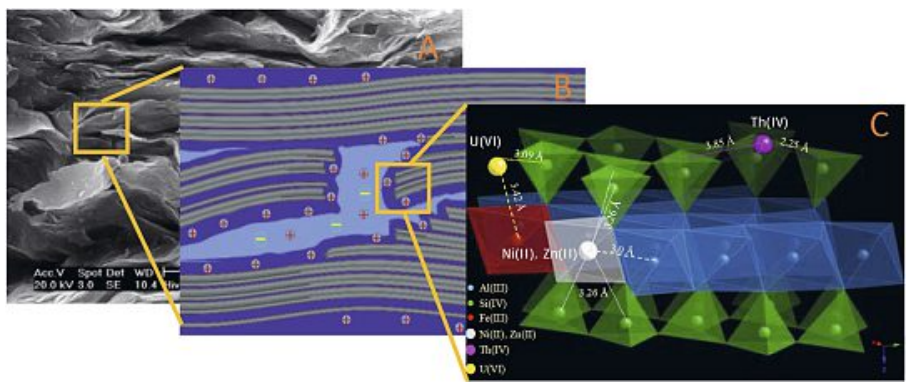

Fig. 3. Scale-dependent phenomena relevant to uptake and transport of radionuclides in compacted clays. From left to right: Electron microscope image of a compacted clay showing the complex assembly of clay particles and inter-particle pores (A); a simplified 2D model for clay electrolyte interface showing individual clay particles, diffuse double layer on the external surface and interlayer (dark blue) enriched with cations and bulk electrolyte solution in macrospores (light blue) (B); nuclide specific surface complexation mechanism on the surface of a clay particle (C).

mental pore water composition, mineral surfaces) and determines whether the radionuclide is mobile or retarded due to the (co-)precipitation or adsorption. Understanding the retention mechanism at the clay-water interface under relevant geochemical conditions is fundamental for predicting their long-term fate in the environmental conditions. Geochemical and thermodynamic modelling represents an important tool for the interpretation of radionuclide speciation and solubility data and for predicting their behaviour under variable environmental conditions (e.g. ref. [16]). The most advanced models use a thermodynamic approach and incorporate as far as available, mechanistic, as well as structural information about the sorption process. The major advantage of this approach is the possibility to apply the thermodynamic formalism to extrapolate the data obtained in simplified experiments to the complex chemistry relevant for in situ conditions. Thus the continuous development and validation of thermodynamic sorption models for a large range of geochemical conditions are indispensable for the reliable long-term risk assessment of deep geological waste repositories since long-term experiments and experiments under all possible combinations of geochemical conditions are technically not feasible.

\subsection{Development of Mechanistic Sorption Models}

The 2 sites non-electrostatic surface complexation and cation exchange model (2SPNE SC/CE) for montmorillonite and illite ${ }^{[17]}$ has been developed at LES for more than 25 years, and has proven, despite its simplicity, to be the one of the most successful and robust (quasi-)mechanistic sorption modelling approaches. Up to now, sorption data and thus the corresponding sorption model have been produced for single nuclides on illite and montmorillonite covering oxidation states from $+\mathrm{I}$ to $+\mathrm{VI} .^{[18]}$ The $2 \mathrm{SPNE}$ $\mathrm{SC} / \mathrm{CE}$ model describes sorption by a combination of electrostatic binding on planar sites (cation exchange) and inner-sphere surface complexation on amphoteric $(\equiv \mathrm{AlOH}$ or $\equiv \mathrm{SiOH})$ edge sites. The model distinguishes between two types of edge sites referred to as high-affinity/low-capacity sites ('strong sites') and as weakaffinity/high-capacity sites ('weak sites'), respectively. For divalent $\mathrm{Zn}$, the occurrence of the strong and weak sites could be confirmed spectroscopically and by atomistic simulations. ${ }^{[15 a, 19]}$ The exact molecular nature of these adsorption sites, however, has not been fully resolved so far. Hence the understanding of the sorption processes at the clay water interface is important for the development of reliable and realistic sorption models and requires molecular scale information on the sorption mechanisms of different elements (i.e. crystallographic position, type of binding, nature of surface species, solid solution formation). Most important model parameters (e.g. site types, capacities, surface complexation and cation exchange constants) are obtained based on experimental sorption data for single elements on well-characterized pure clay minerals and in simple well defined electrolytes. The 2SPNE SC/ $\mathrm{CE}$ model has been developed based on three types of different experimental data sets: (1) acid/base titration data to derive protolysis reactions and constants; (2) radionuclide sorption edges (trace sorption as function of $\mathrm{pH}$ at fixed ionic strength) and (3) radionuclide sorption isotherms (concentration dependent sorption at fixed $\mathrm{pH}$ and fixed ionic strength). The radionuclide specific surface complexation and cation exchange constants are obtained by modelling all radionuclide specific adsorption data simultaneously until the best fit is achieved. A comprehensive overview of the 2SPNE SC/CE model and most of the systems studied is given in e.g. refs $[17,18,20]$. The development of sorption models on pure reference minerals is extremely important for the prediction of the behaviour of nuclides in complex natural environments. [21] 
The 2SPNE SC/CE model for illite and montmorillonite has been used and tested, in a simplified bottom-up approach, to blindly predict the sorption of a large range of elements on different argillaceous rocks in their respective complex pore waters (e.g. Opalinus Clay, Boda Claystone and bentonite). ${ }^{[22]}$ Since it is intrinsically difficult to carry out experimental studies under all the potential chemical conditions, including the in situ relevant conditions for the repository, sorption studies strongly rely on the thermodynamic modelling approach, in which the most important factors controlling aqueous speciation are: temperature, $\mathrm{pH}$, salinity and redox. However, the presence of solid phases, colloids, organic and inorganic ligands should be also accounted for.

\subsection{Competitive Sorption Phenomena}

Competitive influence of high element concentrations on the sorption of radionuclides, relevant in the safety assessment of radioactive waste repositories has not been addressed in a fully systematic way so far. There are several sources of stable elements in a deep geological radioactive waste repository i.e. intrinsic pore waters salinity, tunnel back fill materials, host rock, dissolution of the spent fuel and vitrified HLW. Particularly, in the near-field, the anoxic corrosion of steel canisters will modify the mineralogical composition of the interface through the formation of ferrous iron-containing minerals, as well as maintain a continuous supply of dissolved Fe(II). ${ }^{[23]}$ All these intrinsic stable metal inventories may considerably influence the sorption of other radionuclides by (partially) blocking the sorption sites on engineered and natural clay barrier systems and thus reduce or even impede the sorption of trace radionuclides. ${ }^{[24]}$

Competitive sorption studies suggest that in mixed electrolyte systems, the sorption of one radionuclide is affected by presence of other ions depending on the nature of the competing cations. Bradbury and Baeyens ${ }^{[25]}$ investigated the competitive sorption between different metals (i.e. Co(II), Ni(II), Zn(II), Eu(III), $\mathrm{Nd}(\mathrm{III}), \mathrm{Am}(\mathrm{III}), \mathrm{Th}(\mathrm{IV})$ and U(VI)) on montmorillonite and concluded that metals with similar chemical properties (e.g. valence state, hydrolysis behaviour) are competitive, whereas metals with different chemical behaviour do not compete. In a competitive sorption study combining sorption experiments, sorption modelling and X-ray absorption spectroscopy (XAS) between Fe(II) and $\mathrm{Zn}$ (II) on synthetic iron montmorillonite, ${ }^{[26]} \mathrm{Zn}$ (II) and Fe(II) were found to be fully competitive for the strong sites if Fe(II) was the predominant element, whereas the sorption of trace Fe(II) was not affected by increasing Zn(II) concentration. The differences were explained by the existence of sorption sites with higher affinity for $\mathrm{Fe}$ (III) (which forms by surface-induced oxidation from the added $\mathrm{Fe}(\mathrm{II})$ ), which are not accessible for $\mathrm{Zn}$ (II). In a recent study on the sorption of $\mathrm{Pb}$ on illite and montmorillonite, competitive sorption experiments with $\mathrm{Pb}$ (II)/Ni(II), $\mathrm{Pb}$ (II)/Co(II), $\mathrm{Pb}$ (II)/ $\mathrm{Zn}$ (II) and $\mathrm{Pb}$ (II)/Eu(III) pairs on Na-IdP indicated, depending on the experimental set-up, partially and/or non-competitive behaviour. ${ }^{[27]}$ While the sorption of trace $\mathrm{Pb}$ was not affected by high $\mathrm{Ni}$ or Eu concentrations, the sorption of $\mathrm{Co}, \mathrm{Ni}$ and $\mathrm{Eu}$ respectively appeared to be at least partially affected by high $\mathrm{Pb}$ concentrations. Although, the competitive sorption of these binary systems could be quantitatively reproduced by modifying the 2SPNE SC/ $\mathrm{CE}$ model, all these results obtained in simple binary systems suggest that competitive sorption is not a straightforward process and highlights the knowledge gaps in understanding the mechanism of single ion uptake on specific sorption sites.

To elucidate these different sorption behaviours, particularly regarding the complexity of in situ conditions and to improve the mechanistic comprehension of sorption and competitive sorption reactions on clay minerals, further investigations focusing on the mineral surface structure and the molecular scale identification of the different surface sites are necessary

\subsection{Surface Precipitation and Structural Incorporation of Radionuclides}

Amongst the most important mechanisms favoring the irreversible sequestration of the contaminant on clays are surface precipitation, structural incorporation into TOT layer and modifications in the interlayer structure. Analysis of Cs sorption onto illite indicates its irreversible fixation caused by the collapse of the Frayed Edge Sites, FES. It has been shown that these sites can also be exfoliated in the presence of divalent ions. ${ }^{[28]}$ The divalent metals present at higher concentrations, e.g. Ni, Co, $\mathrm{Zn}$ and $\mathrm{Fe}$, have a tendency to nucleate neoformed phyllosilicate or LDH on the edges of clay minerals. ${ }^{[29]}$ The identification and characterization of surface precipitates and their relation to the amount of adsorbed species is an essential aspect of the mechanistic sorption model development. ${ }^{[30]}$ Using extended X-ray absorption fine structure (EXAFS), it has been demonstrated, for example, that $\mathrm{Fe}-, \mathrm{Ni}-, \mathrm{Co}-$ and $\mathrm{Zn}$-containing precipitates can form when clay minerals and $\mathrm{Al}$ - and $\mathrm{Si}$-(hydr)oxides are treated with $\mathrm{Ni}, \mathrm{Co}$ and $\mathrm{Zn}$, and even when the initial metal concentration in solution is under-saturated relative to the pure (hydr)oxide forms of the metal.[29a,31] Several studies suggest that divalent metals can partially and irreversibly be incorporated into the clay structure even at trace concentrations. ${ }^{[19,32]}$ The formation of neoformed phyllosilicates or LDH (with trace or high metal contents) cannot be described by surface complexation models and require more advanced models. One possible approach would be to treat them like a solid solution.[33]

\subsection{Reduction-oxidation Processes}

Reduction-oxidation reactions are key geochemical processes since they strongly influence the mobility of variable valence actinides and fission products such as Tc, Se, Np, U, Pu. ${ }^{[34]}$ The solubility and sorption behaviour of redox-sensitive radionuclides strongly depend on the in situ prevailing Eh conditions and their corresponding oxidation state.

In the Swiss deep geological radioactive waste disposal concept, reducing conditions will prevail, due to the anoxic corrosion of the steel canisters, giving rise to the release of hydrogen gas and the formation of various Fe(II) phases in the vicinity of the steel bentonite interface. In general, the tetravalent oxidation states are less soluble (formation of corresponding oxides) and sorb much stronger due to their strong affinity for hydrolysis even at low $\mathrm{pH}$, where the affinity for surface complexation being directly correlated with the effective charge of the radionuclide. ${ }^{[35]}$ The anionic Se is expected to form weakly sorbing negatively charged or neutral species under all redox conditions, however redox reaction might affect the mobility of selenium by the formation of solubility limiting solids like $\mathrm{FeSe}_{2}$ and $\mathrm{Se}(0)$. [36]

For most of the redox relevant radionuclides except for Se (see section 5.1), the aqueous redox behaviour is thermodynamically well known over the entire Eh-pH range, however not their sorption behaviour. There are substantial experimental gaps concerning the quantification and structural characterization of the sorption of the reduced oxidation states for most of these radionuclides. Most of the information currently available on their sorption behaviour originates from experiments carried out under oxic or anoxic conditions and conducted by using redox stable chemical analogues. The scarcity of such experimental data is explained by the difficulties to perform the measurements under reducing conditions (i.e. very low solubilities, sorption on experimental equipment, difficulty to maintain electrochemically reducing conditions due to low radionuclide concentrations, impossibility to use redox buffering elements such as $\mathrm{Fe}, \mathrm{Sn}$ without interfering with the clay surface). Among the tetravalent actinides only Th(IV) is redox stable and is experimentally used as chemical analogue. The sorption models developed for Th(IV) on illite and montmorillonite are used to derive the sorption database for 
tetravalent actinides in performance assessment. For the trivalent $\mathrm{Pu}$, sorption models obtained on experimental data with $\mathrm{Cm}$ (III) or Am(III) as redox stable chemical analogues are used. ${ }^{[18 a, c, 37]}$

Besides the aqueous redox reactions, which will mostly control the overall aqueous speciation and which require the transfer of electrons between aqueous species (homogenous), there are also the surface-mediated reactions which involve the transfer of electrons between radionuclides and mineral surfaces (heterogeneous) ${ }^{[38]}$ Minerals participating into surface-mediated redox reactions must contain variable valence elements which can change their oxidation state and act as electron donor or electron acceptor. Mineral phases containing redox-active species such Fe or $\mathrm{Mn}$ are the important redox controlling phases in natural systems. Their ability to participate in electron-transfer reactions depends amongst other factors, on the concentration and structural location of the redox sensitive elements. ${ }^{[39]}$ The rates and extents of redox reactions are controlled by the physico-chemical properties (e.g. redox and sorption potential, electron conductivity, etc.) depending in turn on factors like composition, crystallinity, structural ordering and particle size) of the minerals. ${ }^{[40]}$ The major focus of redox relevant studies, in the last decade, and thus most of the available data are related to the influence of iron-bearing clay minerals, oxides, hydroxides and sulfides on immobilization of $U$, $\mathrm{Pu}, \mathrm{Np}, \mathrm{Se}$ and Tc. ${ }^{[41]}$ In the case of iron-containing clays, surfaceinduced redox reactions are assumed to occur through electron transfer to structural or sorbed Fe. Acquiring a sound molecular scale understanding of surface induced electron transfer processes is a challenging task. However, the importance of these reaction paths has been recognized and is reflected by the related increasing number of studies (e.g. refs [38a,39,42]).

Only few studies have succeeded in describing coupled sorption/redox reactions on clay minerals via mechanistic surface complexation models so far. ${ }^{[43]}$ Such thermodynamic models are particularly relevant for a comprehensive prediction in natural systems. Soltermann et al., ${ }^{[44]}$ for example, described the coupled sorption/ oxidation of $\mathrm{Fe}$ (II) on $\mathrm{Fe}$ (III) containing montmorillonite with the 2SPNE SC/CE model by considering the formation of ferric surface complexes $\left(\equiv \mathrm{S}^{\mathrm{S}} \mathrm{OFe}^{2+}\right)$ along with ferrous surface complexes $\left(\equiv \mathrm{S}^{\mathrm{S}} \mathrm{OFe}^{+}\right)$as a function of Eh-pH. The developed model is capable of describing the sorption of $\mathrm{Fe}$ (II) on different montmorillonites over a wider range of $\mathrm{pH}$ and Eh conditions, however it does not account for the intrinsic redox properties of the clay mineral itself.

\section{Chemistry of Dose-relevant Nuclides}

The term 'dose-relevant nuclides' refers to the group of longliving radioisotopes responsible for the long-term radiological impact of the repository on the biosphere, while 'dose-determining nuclides' contribute to the total dose calculated in a specific case of a performance assessment study. Fig. 4 shows the long-term evolution of some important nuclides of the inventory. Typically, dose-relevant nuclides are the species showing weak or no sorp- tion and increased mobility under the in situ repository conditions. The retention and mobility of radionuclides depend on their chemical speciation. The stability field and aqueous speciation of the dose-relevant nuclides under given environmental conditions is estimated on the basis of chemical equilibrium thermodynamics. This information, especially the charge and the nature of the dominating aqueous complexes under specified chemical conditions is needed to adjust sorption values to these chemical conditions. Furthermore, dose-relevant nuclides generally cannot be dissolved from solidified waste in unlimited quantities. In most cases secondary solids containing the radionuclides are expected to form in the pore waters surrounding the corroding waste form due to known solid-liquid equilibria.

\subsection{Anionic Species}

Long-lived radionuclides that are stable in aqueous solution at the repository relevant conditions as negatively charged anionic species are of special concern in performance assessments of deep geological repositories. Most common rock-forming minerals, and clay minerals in particular, have negatively charged surfaces. Therefore the anions do not adsorb or only weakly interact with mineral surfaces and thus have higher mobility contributing significantly to radiological impact of the repository, compared to the cationic species strongly retarded in argillaceous rocks. By contrast, layered double hydroxide (LDH) phases could be a partial trap for anionic radionuclides. LDH phases are characterized by a layered structure where the layers have permanent positive surface charges which are compensated by anions like $\mathrm{Cl}^{-}$, $\mathrm{I}^{-}, \mathrm{CO}_{3}{ }^{2-}, \mathrm{SO}_{4}^{2-}$ or $\mathrm{SeO}_{4}{ }^{2-}$ located in the interlayer regions. The most important dose-relevant anionic species are $\mathrm{Cl}-36$, Se-79, Tc-99 and I-129. The chemistry as well as the origin and initial waste forms of Cl-36, Se-79 and I-129 have been discussed in detail elsewhere. ${ }^{[8]}$ Since sorption phenomena do not contribute significantly to the retention of these elements, the possibility of reducing their concentration in the aqueous solution via sparingly soluble solid phases or solid solutions has been intensively investigated.

The isotope I-129 is one of the major fission products in spent fuel of nuclear power plants, and the amounts of I-129 produced can be estimated fairly well. Because of its enormous half-life of $1.6 \cdot 10^{7}$ years, it has a low activity in nuclear waste compared with other fission products, but it outlasts all other radionuclides (Fig. 4). Under repository conditions it dissolves exclusively as iodide, $\mathrm{I}^{-}$. A potential solubility-limiting solid for isotope I-129 would be $\mathrm{AgI}(\mathrm{cr})$. However, more than $98 \%$ of $\mathrm{Ag}$ in Swiss radioactive waste will be stored in the L/ILW repository, while more than $99 \%$ of I-129 is present in SF. Under the given conditions, these elements cannot come together to form a solid phase. Another potential iodide-incorporating solid could also be present in cementitious systems, AFm- $\mathrm{I}_{2}\left(3 \mathrm{CaO} \cdot \mathrm{Al}_{2} \mathrm{O}_{3} \cdot \mathrm{CaI}_{2} \cdot 12 \mathrm{H}_{2} \mathrm{O}\right)$, which belongs to the above-mentioned LDH family of compounds. However,
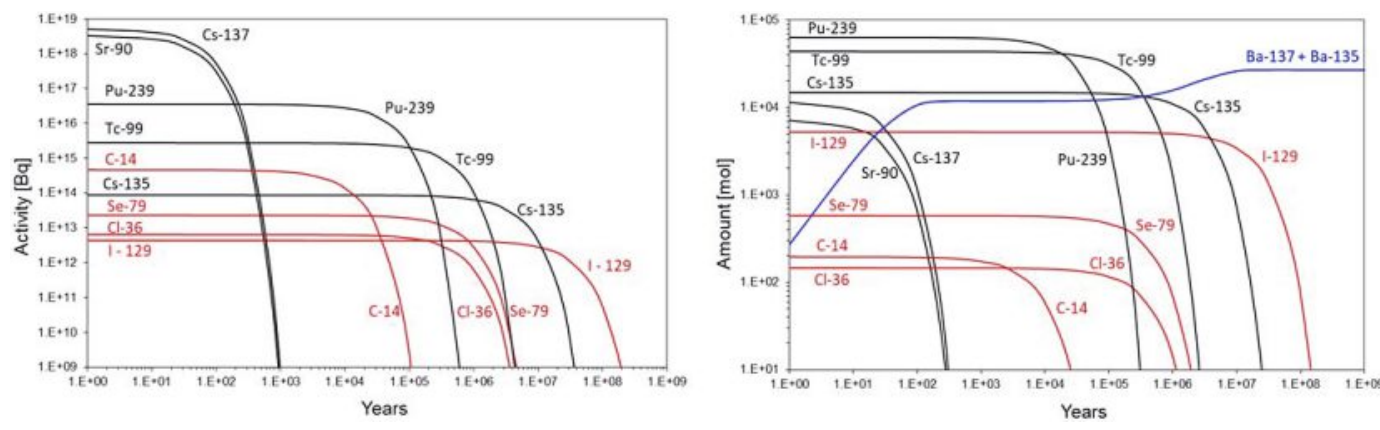

Fig. 4. Time evolution of total activities (a) and total amounts in mol (b) of some important doserelevant radionuclides (black and red lines) and stable isotopes (blue line) in the repository for high level waste. Red lines indicate dosedetermining radionuclides according to a performance assessment study for the demonstration of disposal feasibility. ${ }^{[2]}$ Stable Ba137 and $\mathrm{Ba}-135$ is produced by the decay of Cs-137 and Cs-135, respectively. Initial inventories taken from MIRAM14, [1] half-lives taken from nucleonica.com. 
experimental investigations reveal ${ }^{[45]}$ that this phase will not be thermodynamically stable under repository conditions. It seems improbable that hitherto major chemical solubility and retardation phenomena have been overlooked and that uncertainties regarding iodine retardation can be reduced. ${ }^{[8]}$

Cl-36 is produced by neutron activation of traces of stable Cl-35 in nuclear fuel and reactor steel. This isotope is omnipresent

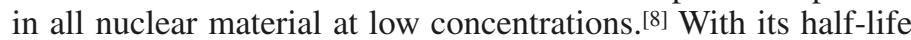
of $3.0 \cdot 10^{5}$ years, $\mathrm{Cl}-36$ is the longest-lived major neutron activation product in nuclear waste. It dissolves exclusively as chloride, $\mathrm{Cl}^{-}$. Chloride forms highly soluble salts with all major and minor components of ground and surface waters, and no significant retardation effects are expected for Cl-36.

Se-79 is a minor fission product and it is also produced by neutron activation of traces of stable Se-78 in nuclear material. The half-life of Se-79 has been controversial for a long time, the now established value is $3.3 \cdot 10^{5}$ years. ${ }^{[46]} \mathrm{Se}$ is a redox-sensitive element which dissolves as selenate, $\mathrm{SeO}_{4}{ }^{2-}$ under oxidizing conditions and can be reduced to selenite, $\mathrm{SeO}_{3}{ }^{2-}$ and $\mathrm{HSeO}_{3}{ }^{-}$, to selenium in redox state zero, $\mathrm{Se}(\mathrm{aq})$, and finally to selenide, $\mathrm{HSe}^{-}$, under strongly reducing conditions. Hence, at all feasible redox and $\mathrm{pH}$ conditions of geological repositories, $\mathrm{Se}-79$ is expected to form negatively charged or neutral species. Potentially, solubility limiting solids are $\mathrm{FeSe}_{2}(\mathrm{cr})$ and $\mathrm{Se}(\mathrm{cr})$. However, no conclusive solubility study of $\mathrm{FeSe}_{2}(\mathrm{cr})$ has been published yet, and the solubility of $\mathrm{Se}(\mathrm{cr})$ with respect to $\mathrm{Se}(\mathrm{aq})$ is highly speculative.

Tc-99 is one of the most abundant fission products with a halflife of $2.1 \cdot 10^{5}$ years. In the Swiss nuclear waste inventory the activity of fission products first is dominated by the medium-lived isotopes Cs-137 (30.0 years) and Sr-90 (28.8 years), but after a few hundred years until about 1 Mio years Tc-99 is the most active fission product (Fig. 4). Tc is a redox-sensitive element, it dissolves to pertechnetate, $\mathrm{TcO}_{4}^{-}$, under oxidizing conditions, but forms Tc(IV) solids and aqueous species under reducing conditions. In a HLW repository with spent fuel or vitrified waste enclosed in massive steel canisters, reducing conditions will prevail and Tc-99 is expected in the chemical form of the solid $\mathrm{TcO}_{2}(\mathrm{am})$ and the dominating aqueous species $\mathrm{TcO}(\mathrm{OH})_{2}(\mathrm{aq})$, with a solubility in the range of $10^{-8}$ to $10^{-9} \mathrm{~mol} / \mathrm{L}$ at $3<\mathrm{pH}<10$.

\subsection{C-14}

Carbon-14 is an important radionuclide in the inventory of radioactive waste and is considered to be a key radionuclide contribution to the radiological impact of the repository. In Switzerland, the ${ }^{14} \mathrm{C}$ inventory in a cement-based repository for low- and intermediate-level radioactive waste is mainly associated with activated steel $(\sim 75 \%)$. In light water reactors (LWR), ${ }^{14} \mathrm{C}$ is the product of mainly ${ }^{14} \mathrm{~N}$ activation $\left({ }^{14} \mathrm{~N}(\mathrm{n}, \mathrm{p}){ }^{14} \mathrm{C}\right)$. Anaerobic corrosion of the activated steel will determine the time-dependent release of ${ }^{14} \mathrm{C}$-bearing compounds from the cementitious near field into the host rock. Significant experimental efforts have been undertaken to investigate the source and release rate of C-14 containing molecules, their stability at repository conditions and the transport mechanism. C-14 can be released in a variety of organic and inorganic chemical forms depending on the nature of the waste material and the chemical conditions of the near field. C-14 can decay within a disposal facility if the C-14-bearing compounds are retained by interaction with the materials of the engineered barrier. Inorganic carbon, i.e. ${ }^{14} \mathrm{CO}_{2}$ (and its bases), is expected to precipitate as calcium carbonate within a cement-based repository or undergo ${ }^{14} \mathrm{CO}_{3}{ }^{2-}$ isotopic exchange with solid calcium carbonate. Experimental studies show that corrosion of activated steel in the cementitious repository leads to release of aqueous low molecular weight organic molecules such as aliphatic hydrocarbons, carboxylates and alcohols ${ }^{[4]}$ or alkanes and alkenes in gaseous phase. ${ }^{[48]}$ The volatile species such as methane have very low reactivity and could be particularly mobile especially at the conditions of partial saturation. ${ }^{[49]}$

\section{Radionuclide Mobility}

Transport of radionuclides in argillaceous rocks and compacted clays is dominated by diffusive fluxes. In addition to the surface complexation phenomena, the negatively charged basal surfaces of clay minerals favor enrichment of cationic species (electrostatic sorption) and depletion of negatively charged species (anion exclusion) from the near surface region (Fig. 3). It is often assumed that diffusive transport takes place in aqueous phases whereas the adsorbed species (both surface complexation and electrostatic phys-sorption) are considered as immobile. Accordingly the radionuclide mobility is impeded by sorption on mineral surfaces and longevity of the transport pathway imposed by the complex geometry of the pore space. The latter mechanism is particularly important for anions, which are known to have extremely weak sorption affinity. Anion exclusion leads to reduction of the anion accessible porosity and substantial decrease of anionic mobility in argillaceous rocks. Recent experiments[50] show, however, that adsorbed species at the mineral surfaces could be mobile and contribute to the diffusive flux significantly. Also the cationic species enriched at the negatively charged surface, especially the highly charged ones, promptly form ionic pairs which enable co-transport of anionic species. These observations emphasize the importance of the coupled radionuclide sorption and transport modelling accompanied with corresponding experimental studies. The contribution of surface and aqueous fluxes depend on the radionuclide speciation which is, in turn, controlled by the solution chemistry.

\section{Outlook and Further Research Directions}

The safety of the waste disposal facilities has to be demonstrated for several $10^{5}-10^{6}$ years. These timescales are way beyond our experimental capabilities and emphasize the importance of geochemical models development and predictive reactive transport simulations. The safety of concepts for geological disposal of radioactive waste rely on fundamental knowledge of radionuclide aquatic chemistry and their interaction with the mineral surfaces. The assessment of the disposal safety is implemented using a conservative approach implying that only well quantified processes are taken into account and unknowns are introduced as model uncertainties. To give few examples, the speciation and retention of C-14 containing species is poorly characterized. Accordingly the C-14 contribution to the radiological dose of the repository is performed neglecting any potential for the retention. Deeper understanding of the radionuclide chemistry and the coupling to the transport phenomena is a potential to substantially reduce the conservativism included in the models used for the performance assessment.

It is expected by geochemical reasoning that most radionuclides, dissolved at trace concentration levels in nature will form solid-solutions with major element solids. However, until now only one case of such a solid-solution system is well established in performance assessments of geological repositories: the $\mathrm{Ra}-$ $\mathrm{Ba}$-sulphate system. Actually, the formation of ( $\mathrm{Ra}, \mathrm{Ba}) \mathrm{SO}_{4}$ solidsolutions was already used by Marie and Pierre Curie to enrich their newly discovered element radium to weighable amounts in their lab. Considering the $(\mathrm{Ra}, \mathrm{Ba}) \mathrm{SO}_{4}(\mathrm{cr})$ solid-solution in model calculations can reduce the solubility limit of $\mathrm{Ra}$ by orders of magnitude with respect to calculations considering only pure $\mathrm{RaSO}_{4}(\mathrm{cr}){ }^{[51]}$ But can we be sure that enough $\mathrm{Ba}$ is available to form the solid-solution? Most probably yes, because stable Ba137 and $\mathrm{Ba}-135$ is produced in the waste itself by the decay of Cs-137 and Cs-136, respectively (Fig. 4b).

It has been emphasized that the mobility of radionuclides depends on the $\mathrm{pH}$-Eh conditions in the repository near field and the confining rock units. The repository near field is expected to maintain reducing conditions at which the hazardous redox sensitive nuclides such as $\mathrm{U}, \mathrm{Pu}, \mathrm{Np}$ are expected to be stable in their highly immobile tetravalent state. It may come as a surprise that sorption models for tetravalent radionuclides are not based on 
extensive experimental studies due to inherent experimental difficulties associated with the low solubility limits and difficulties to maintain the system at reducing conditions. Thorium is the only actinide in the oxidation state 4+ whose sorption has been studied in detail in a wide range of repository relevant conditions. The existing sorption models for redox-sensitive radionuclides in the valence state $4+$ are based on the chemical analogy argument (e.g. $\mathrm{Th}^{4+}$ ) and thermodynamics-based extrapolations of experimental results to repository relevant conditions. Punctual experimental studies support the validity of these assumptions. More systematic experimental studies supported by molecular scale characterization and modelling of radionuclide retention on mineral surfaces are needed.

The sorption competition phenomena, the sorption reversibility and the surface-mediated redox reaction are one of several fundamental research topics needing deeper experimental studies and further mechanistic model development. Exemplary, a number of open research questions related to the mobility of the adsorbed species, reversibility of the sorption phenomena and the surface-mediated redox reactions are being addressed within the Joint European Program funded within the HORIZON 2020 EC program.

\section{Acknowledgements and Disclaimer}

The authors acknowledge long-standing collaboration and partial financial support of Nagra. However, the views, opinions and conclusions of the authors expressed in the manuscript do not necessarily state or reflect those of Nagra. The authors acknowledge the cofunding from Horizon 2020 EURAD project Grant ID 847593

Received: September 8, 2020

[1] Nagra, 'Modellhaftes Inventar für radioaktive Materialien MIRAM 14.', 2014.

[2] Nagra, 'Demonstration of disposal feasibility for spent fuel, vitrified highlevel waste and long-lived intermediate-level waste', 2002.

[3] ENSI-G03, 'Spezifische Auslegungsgrundsätze für geologische Tiefenlager und Anforderungen an den Sicherheitsnachweis. Richtlinie für die schweizerischen Kernanlagen', 2009.

[4] W. Hummel, J. W. Schneider, Chimia 2005, 59, 909, https://doi.org/10.2533/000942905777675444.

[5] L. Johnson, C. Poinssot, C. Ferry, P. Lovera, 'Estimates of instant release fraction for UO2 and MOX fuel at $\mathrm{t}=0^{\prime}, \mathbf{2 0 0 4}$

[6] a) E. Curti, A. Froideval-Zumbiehl, I. Gunther-Leopold, M. Martin, A. Bullemer, H. Linder, C. N. Borca, D. Grolimund, J. Nucl. Mater. 2014, 453, 98, https://doi.org/10.1016/j.jnucmat.2014.07.003; b) E. Curti, A. Puranen, D. Grolimund, D. Jadernas, D. Sheptyakov, A. Mesbah, Environ. Sci. Proc. Impacts 2015, 17, 1760, https://doi.org/10.1039/c5em00275c

[7] E. Curti, 'Glass Dissolution Parameters: Update for Entsorgungsnachweis', 2003.

[8] W. Hummel, 'Chemistry of selected dose-relevant radionuclides', 2017.

[9] W. Heep, Int. Zeit. f. Kernenergie 2007, 52, 263.

[10] W. Hummel, M. Filella, D. Rowland, Sci. Tot. Environ. 2019, 692, 49, https://doi.org/10.1016/j.scitotenv.2019.07.161.

[11] F. J. Pearson, Jr., U. Berner, 'Nagra Thermochemical Data Base I. Core Data.', 1991.

[12] F. J. Pearson, Jr., U. Berner, W. Hummel, 'Nagra Thermochemical Data Base II. Supplemental Data 05/92.', 1992.

[13] W. Hummel, U. Berner, E. Curti, F. J. Pearson, T. Thoenen, 'Nagra/PSI Chemical Thermodynamic Data Base $01 / 01$ ', 2002.

[14] T. Thoenen, W. Hummel, U. Berner, E. Curti, 'The PSI/Nagra Chemical Thermodynamic Database 12/07', 2014.

[15] a) S. V. Churakov, R. Dähn, Environ. Sci. Technol. 2012, 46, 5713; b) A. Keri, R. Dahn, M. Marques Fernandes, A. C. Scheinost, M. Krack, S. V. Churakov, Environ. Sci. Technol. 2020, 54, 11886, https://doi.org/10.1021/acs.est.9b07962; c) I. C. Bourg, G. Sposito, A. C. M. Bourg, J. Coll. Interf. Sci. 2007, 312, 297, https://doi.org/10.1016/j.jcis.2007.03.062

[16] a) B. Baeyens, M. Marques Fernandes, in 'Surface and Interface Chemistry of Clay Minerals', Eds. R. Schoonheydt, C. T. Johnston, F. Bergaya, Elsevier, 2018, p. 125; b) C. Tournassat, J. A. Davis, C. Chiaberge, S. Grangeon, I. C. Bourg, Environ. Sci. Technol. 2016, 50, 13436, https://doi.org/10.1021/acs.est.6b04677; c) D. Kulik, Rev. Mineral. Geochem. 2009, 70, 125, https://doi.org/10.2138/rmg.2009.70.4; d) 'Surface complexation models of adsorption', Marcel Dekker Inc., New York, 2002.
[17] a) M. H. Bradbury, B. Baeyens, J. Contam. Hydrol. 1997, 27, 223; b) M. H. Bradbury, B. Baeyens, Geochim. Cosmochim. Acta 2009, 73, 1004 https://doi.org/10.1016/j.gca.2008.11.016.

[18] a) B. Baeyens, M. H. Bradbury, 'The development of a thermodynamic sorption database for montmorillonite and the application to bentonite', 2017; b) B. Baeyens, M. Marques Fernandes, in 'Developments in Clay Science', Vol. 9, Eds. R. Schoonheydt, C. T. Johnston, F. Bergaya, Elsevier, 2018, p. 125, https://doi.org/10.1016/B978-0-08-102432-4.00005-6; c) M. H. Bradbury, B. Baeyens, 'The development of a thermodynamic sorption data base for illite and the application to argillaceous rocks. PSI Bericht $\mathrm{Nr}$ 17-06. Paul Scherrer Institut, Villigen PSI and NTB 17-14, Nagra, Wettingen, Switzerland', 2017.

[19] R. Dähn, B. Baeyens, M. H. Bradbury, Geochim. Cosmochim. Acta 2011, 75 , 5154.

[20] a) B. Baeyens, M. H. Bradbury, J. Contam. Hydrol. 1997, 27, 199; b) M. H. Bradbury, B. Baeyens, Geochim. Cosmochim. Acta 2009, 73, 990.

[21] a) J. A. Davis, J. A. Coston, D. B. Kent, C. C. Fuller, Environ. Sci. Technol. 1998, 32, 2820, https://doi.org/10.1021/es980312q; b) T. E. Payne, V. Brendler, M. Ochs, B. Baeyens, P. L. Brown, J. A. Davis, C. Ekberg, D. A. Kulik, J. Lutzenkirchen, T. Missana, Y. Tachi, L. R. Van Loon, S. Altmann, Environ. Model. Software 2013, 42, 143 , https://doi.org/10.1016/j.envsoft.2013.01.002.

[22] a) M. H. Bradbury, B. Baeyens, Appl. Clay Sci. 2011, 52, 27, https://doi.org/10.1016/j.clay.2011.01.022; b) M. Marques Fernandes, N. Ver, B. Baeyens, Appl. Geochem. 2015, 59, 189, https://doi.org/10.1016/j.apgeochem.2015.05.006.

[23] a) J. Hadi, P. Wersin, V. Serneels, J. M. Greneche, Clays Clay Miner. 2019 67, 111, https://doi.org/10.1007/s42860-019-00012-5; b) M. H. Bradbury, U. Berner, E. Curti, W. Hummel, G. Kosakowski, T. Thoenen, 'The Long Term Geochemical Evolution of the Nearfield of the HLW Repository', 2012.

[24] M. H. Bradbury, M. Marques Fernandes, B. Baeyens, 'Estimates of the influence of radionuclide solubility limits and sorption competition on the sorption values in the SDBs of MX-80 bentonite and Opalinus Clay', 2017.

[25] M. H. Bradbury, B. Baeyens, Geochim. Cosmochim. Acta 2005, 69, 4187.

[26] D. Soltermann, M. Marques Fernandes, B. Baeyens, J. MiehéBrendlé, R. Dähn, Environ. Sci. Technol. 2014, 48, 190 , https://doi.org/10.1021/es402783r.

[27] M. Marques Fernandes, B. Baeyens, Appl. Geochem. 2019, 100, 190, https://doi.org/10.1016/j.apgeochem.2018.11.005.

[28] a) A. Benedicto, T. Missana, A. M. Fernández, Environ. Sci. Technol. 2014, 48, 4909; b) A. J. Fuller, S. Shaw, M. B. Ward, S. J. Haigh, J. F. W. Mosselmans, C. L. Peacock, S. Stackhouse, A. J. Dent, D. Trivedi, I. T. Burke, Appl. Clay Sci. 2015, 108, 128; c) C. B. Durrant, J. D. Begg, A. B. Kersting, M. Zavarin, Sci. Tot. Environ. 2018, 610, 511

[29] a) R. Dähn, A. M. Scheidegger, A. Manceau, M. L. Schlegel, B. Baeyens, M. H. Bradbury, M. Morales, Geochim. Cosmochim. Acta 2002, 66, 2335 b) M. L. Schlegel, A. Manceau, L. Charlet, D. Chateigner, J.-L. Hazemann, Geochim. Cosmochim. Acta 2001, 65, 4155 .

[30] a) A. M. Scheidegger, G. M. Lamble, D. L. Sparks, J. Coll. Interf. Sci. 1997 , 186, 118; b) R. G. Ford, A. C. Scheinost, D. L. Sparks, 'Frontiers in metal sorption/precipitation mechanisms in soil mineral surfaces', in 'Advances in Agronomy', Vol. 74, 2001, pp 41-62.

[31] a) S. N. Towle, J. R. Bargar, G. E. Brown Jr., G. A. Parks, J. Coll. Interf. Sci. 1997, 187, 62; b) A. M. Scheidegger, D. G. Strawn, G. M. Lamble, D. L. Sparks, Geochim. Cosmochim. Acta 1998, 62, 2233; c) A. Manceau, M. L. Schlegel, K. L. Nagy, L. Charlet, J. Coll. Interf. Sci. 1999, 220, 181; d) H. A. Thompson, G. A. Parks, G. E. Brown Jr., Clays Clay Miner. 1999, 47, 425; e) H. A. Thompson, G. A. Parks, G. E. Brown Jr., Geochim. Cosmochim. Acta 1999, 63, 1767; f) J. D. Morton, J. D. Semrau, K. F. Hayes, Geochim. Cosmochim. Acta 2001, 65, 2709; g) M. L. Schlegel, A. Manceau, L. Charlet, D. Chateigner, J. L. Hazemann, Geochim. Cosmochim. Acta 2001, 65,$4155 ;$ h) R. Dähn, A. M. Scheidegger, A. Manceau, M. L. Schlegel, B. Baeyens, M. H. Bradbury, J. Synchrotron Radiat. 2001, 8, 533; i) S. Lee, P. R. Anderson, B. A. Bunker, C. Karanfil, Environ. Sci. Technol. 2004, 38, 5426; j) Y. Zhu, E. J. Elzinga, Environ. Sci. Technol. 2014, 48, 4937, https://doi.org/10.1021/es500579p.

[32] a) S. V. Churakov, R. Dähn, Environ. Sci. Technol. 2012, 46, 5713, https://doi.org/10.1021/es204423k; b) C. Tournassat, S. Grangeon, P. Leroy, E. Giffaut, Am. J. Sci. 2013, 313, 395, https://doi.org/10.2475/05.2013.01; c) A. Kéri, R. Dahn, M. Marques Fernandes, A. C. Scheinost, M. Krack, S. V. Churakov, Environ. Sci. Technol. 2020, 54, 11886, https://doi.org/10.1021/acs.est.9b07962.

[33] a) Y. Tardy, B. Fritz, Clay Miner. 1981, 16, 361 , https://doi.org/10.1180/claymin.1981.016.4.05; b) K. Rozov, U. Berner, C. Taviot-Gueho, F. Leroux, G. Renaudin, D. Kulik, L. W. Diamond, Cement Concrete Res. 2010, 40, 1248 , https://doi.org/10.1016/j.cemconres.2009.08.031; c) L. Aimoz, D. A Kulik, E. Wieland, E. Curti, B. Lothenbach, U. Mäder, Appl. Geochem. 2012, 27, 2117, https://doi.org/10.1016/j.apgeochem.2012.06.006; d) U. Berner, D. A. Kulik, G. Kosakowski, Phys. Chem. Earth 2013, 64, 46, https://doi.org/10.1016/j.pce.2013.03.007.

[34] a) R. Guillaumont, T. Fanghänel, J. Fuger, I. Grenthe, V. Neck, D. A. Palmer, M. H. Rand, 'Update on the chemical thermodynamics of Uranium, 
Neptunium, Plutonium, Americium and Technetium', Vol. 5, Elsevier, Amsterdam, 2003; b) M. A. Denecke, N. Bryan, S. Kalmykov, K. Morris, F. Quinto, in 'Experimental and Theoretical Approaches to Actinide Chemistry', 2018, p. 378, https://doi.org/10.1002/9781119115557.ch8; c) H. Geckeis, J. Lützenkirchen, R. Polly, T. Rabung, M. Schmidt, Chem. Rev. 2013, 113, 1016, https://doi.org/10.1021/cr300370h; d) A. Olin, B. Nolang, E. G. Osadchii, L.-O. Ohman, E. Rosén, 'Chemical thermodynamics of selenium', Elsevier, Amsterdam; London, 2005.

[35] L. Righetto, G. Bidoglio, G. Azimonti, I. R. Bellobono, Environ. Sci. Technol. 1991, 25, 1913, https://doi.org/10.1021/es00023a012.

[36] E. Curti, L. Aimoz, A. Kitamura, J. Radioanal. Nucl. Chem. 2013, 295, 1655, https://doi.org/10.1007/s10967-012-1966-9.

[37] B. Baeyens, T. Thoenen, M. H. Bradbury, M. Marques Fernandes, 'Sorption data bases for argillaceous rocks and bentonite for the provisional safety analyses for SGT-E2', Switzerland, 2014.

[38] a) M. V. Schaefer, C. A. Gorski, M. M. Scherer, Environ. Sci. Technol. 2011, 45, 540; b) E. Liger, L. Charlet, P. Van Cappellen, Geochim. Cosmochim. Acta 1999, 63, 2939, https://doi.org/10.1016/s0016-7037(99)00265-3.

[39] a) C. A. Gorski, M. Aeschbacher, D. Soltermann, A. Voegelin, B. Baeyens, M. Marques Fernandes, T. B. Hofstetter, M. Sander, Environ. Sci. Technol. 2012, 46, 9360, https://doi.org/10.1021/es3020138; b) C. A. Gorski, L. Klupfel, A. Voegelin, M. Sander, T. B. Hofstetter, Environ. Sci. Technol. 2012, 46, 9369, https://doi.org/10.1021/es302014u; c) C. A. Gorski, L. E. Klupfel, A. Voegelin, M. Sander, T. B. Hofstetter, Environ. Sci. Technol. 2013, 47, 13477, https://doi.org/10.1021/es403824x.

[40] a) A. G. Ilgen, R. K. Kukkadapu, K. Leung, R. E. Washington, Environ. Sci. Nano 2019, 6, 1704, https://doi.org/10.1039/c9en00228f; b) A. C. Scheinost, L. Charlet, Environ. Sci. Technol. 2008, 42, 1984, https://doi.org/10.1021/es071573f.

[41] a) D. D. Boland, R. N. Collins, T. E. Payne, T. D. Waite, Environ. Sci. Technol. 2011, 45, 1327, https://doi.org/10.1021/es101848a; b) D. P. Jaisi, H. L. Dong, A. E. Plymale, J. K. Fredrickson, J. M. Zachara, S. Heald, C. X. Liu, Chem. Geol. 2009, 264, 127, https://doi.org/10.1016/j.chemgeo.2009.02.018; c) R. Kirsch, D. Fellhauer, M. Altmaier, V. Neck, A. Rossberg, T. Fanghanel, L. Charlet, A. C. Scheinost, Environ. Sci. Technol. 2011, 45, 7267, https://doi.org/10.1021/ es200645a; d) A. C. Scheinost, R. Steudtner, R. Hubner, S. Weiss, F. Bok, Environ. Sci. Technol. 2016, 50, 10413, https://doi.org/10.1021/acs. est.6b02399; e) D. M. Singer, S. M. Chatman, E. S. Ilton, K. M. Rosso, J. F. Banfield, G. A. Waychunas, Environ. Sci. Technol. 2012, 46, 3821, https://doi.org/10.1021/es203878c; f) E. Yalcintas, A. C. Scheinost, X. Gaona, M. Altmaier, Dalton Trans. 2016, 45, 17874, https://doi.org/10.1039/c6dt02872a.

[42] a) V. Alexandrov, K. M. Rosso, J. Phys. Chem. C 2013, 117, 22880, https://doi.org/10.1021/jp4073125; b) D. E. Latta, A. Neumann, W. A.
P. J. Premaratne, M. M. Scherer, ACS Earth Space Chem. 2017, 1, 197, https://doi.org/10.1021/acsearthspacechem.7b00013; c) A. Neumann, T. L. Olson, M. M. Scherer, Environ. Sci. Technol. 2013, 47, 6969, https://doi.org/10.1021/es304744v; d) A. Neumann, L. Wu, W. Li, B. L. Beard, C. M. Johnson, K. M. Rosso, A. J. Frierdich, M. M. Scherer, Environ. Sci. Technol. 2015, 49, 2786, https://doi.org/10.1021/es504984q; e) A. Kéri, R. Dahn, M. Marques Fernandes, A. C. Scheinost, M. Krack, S. V. Churakov, Environ. Sci. Technol. 2020, https://doi.org/10.1021/acs.est.9b07962.

[43] a) N. L. Banik, R. Marsac, J. Lützenkirchen, C. M. Marquardt, K. Dardenne, J. Rothe, K. Bender, H. Geckeis, Geochim. Cosmochim. Acta 2017, 215, 421, https://doi.org/https://doi.org/10.1016/j.gca.2017.08.008; b) R. Marsac, N. L. Banik, J. Lützenkirchen, C. M. Marquardt, K. Dardenne, D. Schild, J. Rothe, A. Diascorn, T. Kupcik, T. Schäfer, H. Geckeis, Geochim. Cosmochim. Acta 2015, 152, 39, https://doi.org/10.1016/j.gca.2014.12.021.

[44] D. Soltermann, B. Baeyens, M. H. Bradbury, M. Marques Fernandes, Environ. Sci. Technol. 2014, 48, 8698, https://doi.org/10.1021/es501902f.

[45] L. Aimoz, E. Wieland, C. Taviot-Guého, R. Dähn, M. Vespa, S. V. Churakov, Environ. Sci. Technol. 2012, 47, 3874.

[46] G. Jorg, R. Buhnemann, S. Hollas, N. Kivel, K. Kossert, S. Van Winckel, C. L. V. Gostomski, Appl. Radiat. Isotopes 2010, 68, 2339, https://doi.org/10.1016/j.apradiso.2010.05.006.

[47] a) B. Z. Cvetkovic, J. Rothardt, A. Buttler, D. Kunz, G. Schlotterbeck, E. Wieland, Environ. Eng. Sci. 2018, 35, 447, https://doi.org/10.1089/ees.2017.0216; b) B. Z. Cvetković, G. Salazar, D. Kunz, J. Tits, S. Szidat, E. Wieland, Radiocarbon 2018, 60, 1711, https://doi.org/10.1017/RDC.2018.90.

[48] T. Guillemot, B. Z. Cvetković, D. Kunz, E. Wieland, Chemosphere 2020 250, 126230, https://doi.org/10.1016/j.chemosphere.2020.126230.

[49] E. Wieland, W. Hummel, Mineral. Mag. 2015, 79, 1275, https://doi.org/10.1180/minmag.2015.079.6.03.

[50] M. A. Glaus, S. Frick, L. R. Van Loon, Geochim. Cosmochim. Acta 2020 , 274, 79, https://doi.org/10.1016/j.gca.2020.01.054.

[51] H. B. Shao, D. A. Kulik, U. Berner, G. Kosakowski, O. Kolditz, Geochem. J. 2009, 43, E37, https://doi.org/10.2343/geochemj.1.0069.

\section{License and Terms}

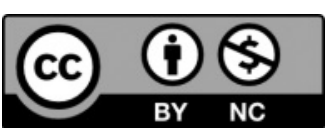

This is an Open Access article under the terms of the Creative Commons Attribution License CC BY_NC 4.0. The material may not be used for commercial purposes.

The license is subject to the CHIMIA terms and conditions: (http:// chimia.ch/component/sppagebuilder/?view=page $\& i d=12$ ).

The definitive version of this article is the electronic one that can be found at https://doi.org/10.2533/chimia.2020.1000 